\title{
Streptococcosis in farmed Litopenaeus vannamei: a new emerging bacterial disease of penaeid shrimp
}

\author{
Ken W. Hasson*, Ernesto Matheu Wyld, Yaping Fan, Sonia W. Lingsweiller, \\ Stephanie J. Weaver, Jinling Cheng, Patricia W. Varner
}

Texas Veterinary Medical Diagnostic Lab, 1 Sippel Rd, College Station, Texas 77843, USA

\begin{abstract}
Presumptive systemic streptococcal infections were detected histologically in farmed Litopenaeus vannamei juveniles submitted from a Latin American country and the bacteria isolated. Characterization work demonstrated that the Gram-positive cocci form chains, grow aerobically and anaerobically, are oxidase- and catalase-negative, non-hemolytic, non-motile, Lancefield Group B positive and PCR positive when amplified with a universal streptococcal primer set. Differing Streptococcus identifications were obtained using API 20 Strep and Biolog systems, the former identifying the isolate as $S$. uberis and the latter as S. parauberis. Injection of specific pathogen-free (SPF) L. vannamei with the bacteria resulted in $100 \%$ mortality by $3 \mathrm{~d}$ post-injection with successful recovery of the agent from moribund test shrimp hemolymph samples. The recovered isolate was used in per os and waterborne exposure studies of SPF L. vannamei with mortalities ranging from 40 to $100 \%$ and 80 to $100 \%$, respectively. Histologic analysis of 5 to 8 moribund shrimp from each exposure method demonstrated that all contained a severe bacteremia characterized by numerous free cocci within the hemolymph and aggregates of vacuolated hemocytes with notable intravacuolar cocci. This unique lesion type was most pronounced within the lymphoid organ and considered pathodiagnostic for this disease. Experimentally induced lesions were identical to those in naturally infected farmed shrimp and the Streptococcus sp. responsible was re-isolated, fulfilling Koch's postulates. Five freeze/thaw cycles of 10 experimentally infected shrimp were performed over a 2 mo period and the bacteria successfully cultured from all shrimp at each interval. These collective findings describe the first reported case of streptococcosis in marine penaeid shrimp in the Western Hemisphere and indicate that the agent may be disseminated via live or frozen infected shrimp.
\end{abstract}

KEY WORDS: Streptococcus $\cdot$ Streptococcosis $\cdot$ Penaeid shrimp $\cdot$ Koch's postulates $\cdot$ Litopenaeus vannamei $\cdot$ Bacteremia

Resale or republication not permitted without written consent of the publisher

\section{INTRODUCTION}

Streptococcosis is an economically important disease that has been reported in over 30 farmed fresh and saltwater fish species including catfish (Shewmaker et al. 2007), tilapia (Eldar et al. 1995), trout (Hoshina et al. 1958, Eldar et al. 1995), salmon (Romalde et al. 2008), red drum (Eldar et al. 1999), flounder (Baeck et al. 2006), yellowtail (Kusuda et al. 1991), hybrid striped bass (Evans et al. 2000) and turbot (Toranzo et al. 1994). The occurrence of streptococcosis in fish appears to be stress related with low grade chronic mortalities seen in some fish species and acute mortalities of 30 to $50 \%$ oc- curring in others as a result of an encephalitis and/or systemic infection affecting multiple organs (Eldar et al. 1995, Ringo \& Gattesoup 1998, Camus et al. 2008). This group of bacteria appear to have no host specificity, are capable of infecting both fish and mammalian species and include Streptococcus iniae, S. agalactiae (S. dificilis), S. phocae and $S$. parauberis with $S$. ictaluri being the most recently described member of this genus to infect an aquaculture fish species (Ringo \& Gattesoup 1998, Shewmaker et al. 2007).

Lethal infections due to Gram-positive cocci in crustaceans are rare and have only been reported in the freshwater prawn Macrobrachium rosenbergii (Cheng 
\& Chen 1998). The disease, 'white muscle disease', causes significant losses in $M$. rosenbergii populations and has been attributed to 2 different species of Lactococcus, L. lactis subsp. lactis and L. garvieae, which are included in the family Streptococcaceae (Vendrell et al. 2006, Wang et al. 2008). Bacterial diseases of farmed marine shrimp are very common, can result in high production losses and are principally caused by opportunistic Gram-negative bacilli corresponding to the Vibrionaceae (Sindermann \& Lightner 1988, Brock \& Main 1994). To date, no reports of Streptococcus infections in penaeid shrimp have been published.

During September 2008, Litopenaeus vannamei, preserved in Davidson's AFA (alcohol, formalin, acid) fixative and originating from 2 separate intensive shrimp culture farms located in a Latin American country, were submitted to the Texas Veterinary Medical Diagnostic Laboratory (TVMDL) for diagnostic evaluation. One farm utilized full strength sea water (29 to $32 \mathrm{ppt}$ ) while the other operated with estuarine water (12 to $18 \mathrm{ppt}$ ). Both farms contained a mixture of lined and unlined ponds with stocking densities of 135 shrimp $\mathrm{m}^{-2}$ and 85 shrimp $\mathrm{m}^{-2}$, respectively. All ponds contained aerators with water quality parameters reported as within normal limits and nighttime dissolved oxygen lows of 2.5 to $3.5 \mathrm{ppm}$ when the disease problem began. Chronic mortality was reported in lined and unlined ponds of both farms and was first observed among juvenile shrimp weighing 6 to $7 \mathrm{~g}$. Losses ranging from 20 to $40 \%$ occurred in ponds during a $3 \mathrm{wk}$ period.

No obvious clinical signs of disease or external lesions were observed, with dead shrimp typically found on pond bottoms. Many of these dead shrimp displayed intact empty exoskeletons with large portions of internal tissue and tail muscle absent as if eaten or degraded from the inside outwards. Histologic and Gram-stain analyses of representative preserved shrimp from each farm demonstrated the presence of a previously unreported systemic bacterial infection characterized by numerous Gram-positive cocci free within the hemolymph of the vasculature and hemal sinuses as well as within cytoplasmic vacuoles of individual hemocytes or small aggregates of these cells. Variable numbers of extracellular cocci, bacteria-laden hemocytes and small hemocytic nodules were detected within the lymphoid organ, heart, gills, skeletal muscle, foregut, midgut, hindgut, nerve cord, connective tissues of both ceca and the hemal sinuses of the antennal gland and hepatopancreas.

Since no published reports of a bacterial septicemia due to a Gram-positive coccus in penaeid shrimp could be found in the literature and this appeared to be a newly emerging disease, the current study was initiated upon the submission of fresh shrimp and hemolymph samples from the affected farms. The objec- tives of the current study were 4-fold: (1) to isolate and perform initial characterization work on the bacterial agent, (2) to fulfill Koch's postulates by reproducing the disease and recovering the isolate from specific pathogen-free (SPF) Litopenaeus vannamei test shrimp using intramuscular injection, waterborne, and per os exposure methods, (3) to describe the histologic changes induced by this disease, and (4) to determine the effect of repeated freezing and thawing cycles on the organism's viability.

\section{MATERIALS AND METHODS}

Bacterial isolation and identification. Chilled shrimp ( $\mathrm{n}=6$ per pond) and corresponding pooled hemolymph samples, originating from a single pond on 2 separate intensive Litopenaeus vannamei farms (hereafter referred to as Farms A and B), were submitted from the affected region (exact location withheld at farm's request). The cephalothorax of each of the 12 shrimp was swabbed with $70 \%$ ethanol, the exoskeleton removed from one side using sterile scissors, and the lymphoid organ exposed for inoculation onto blood agar (BA) plates (tryptic soy agar with 5\% sheep's blood, BBL) using a sterile disposable plastic loop following the methods of Cheng \& Chen (1998). Similarly, each of the 2 pooled hemolymph samples were streaked on BA, and the cultures incubated aerobically and anaerobically overnight at $28^{\circ} \mathrm{C}$ to determine the true hemolytic pattern of the isolates.

Biochemical tests: Pure Streptococcus-like colonies, characterized by the development of numerous small circular white colonies on BA, were isolated from both the shrimp and hemolymph samples originating from the 2 farms after 18 to $24 \mathrm{~h}$ incubation, and then streaked for purity on BA plates. One purified isolate per farm was selected and subjected to oxidase and catalase tests, Gram-staining and biochemical identification using the API 20 Strep strip kit (Biomerieux) following the manufacturer's instructions. The isolates were also inoculated into tryptose broth (Remel) and incubated aerobically at $28^{\circ} \mathrm{C}$ for $18 \mathrm{~h}$ with subsequent wet mount analysis to observe cell morphology. The isolate selected for use in all 3 bioassays was later analyzed with a PathoDx kit (Remel) to determine its Lancefield group designation (Lancefield 1933) and identified using the Omnilog ID system (Biolog) together with an ATCC $S$. porcinus isolate to verify the systems' ability to identify a known Streptococcus sp. These 2 latter tests were performed according to the manufacturer's instructions.

PCR analysis: Bacterial genomic DNA was extracted from 4 separate bacterial samples (Streptococcus-like bacteria from Farm A, Streptococcus-like bacteria from 
Farm B, Streptococcus-like bacteria recovered from Bioassay 2 treatment shrimp, and ATCC $S$. porcinus isolate) following the protocol of Berridge et al. (1998) with modifications. Briefly, bacteria were aerobically cultured in $3 \mathrm{ml}$ of tryptose broth overnight $\left(28^{\circ} \mathrm{C}\right)$ and then equally divided into two $1.5 \mathrm{ml}$ Eppendorf tubes. After centrifugation at $11000 \times g(15 \mathrm{~min})$, the 2 resulting pellets were suspended and combined in $300 \mu$ l of strep lysis buffer (50 mM Tris, $100 \mathrm{mM} \mathrm{NaCl}, 20 \mathrm{mM}$ EDTA, $0.5 \%$ sodium dodecyl sulfate, $\mathrm{pH}$ 6.0) together with $10 \mu \mathrm{l}$ muta-

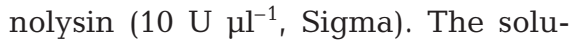
tion was briefly mixed by vortexing, incubated at $37^{\circ} \mathrm{C}$ for $45 \mathrm{~min}$ and then placed in boiling water for $10 \mathrm{~min}$ to inactivate the mutanolysin. Following centrifugation at $16000 \times g(3 \mathrm{~min})$, $100 \mu \mathrm{l}$ of the DNA lysate was transferred to a chromaspin column (Clonetech) according to the manufacturer's instructions, and centrifuged at $700 \times g(15 \mathrm{~min})$. The resulting filtrate was stored at $4^{\circ} \mathrm{C}$ until analyzed by PCR. The PCR reaction mixtures (25 $\mu \mathrm{l}$ ) and thermocycler program used were according to Meiri-Bendek et al. (2002) and utilized their universal 16S rDNA streptococcus primer set (C1: 5'-GCG TGC CTA ATA CAT GCA A-3'; C2: 5' -TAC AAC GCA GGT CCA TCT-3'), which was designed to produce a $207 \mathrm{bp}$ amplicon. The resulting PCR products were run on a $2 \%$ agarose gel $(80 \mathrm{~V}, 40 \mathrm{~min})$, which was then stained by submersion in $0.001 \%$ ethidium bromide (20 min). The gel was then destained under running water for $3 \mathrm{~min}$, the banding pattern visualized by UV transillumination and photographed using a Polaroid Photo-Documentation camera (Fisher Scientific).

Test shrimp. Juvenile SPF Fast Growth line Litopenaeus vannamei (mean weight $=8 \mathrm{~g}$; provided by Shrimp Improvement Systems) were used to conduct 3 separate bioassays. Static 10 gallon (37.9 l) glass aquaria were utilized in each bioassay, filled with $10 \mathrm{l}$ of artificially prepared 30 ppt saltwater (Crystal Sea Bioassay Salt, Marine Enterprises International) and each stocked with 5 or 6 shrimp (4.0 to $4.8 \mathrm{~g} \mathrm{l}^{-1}$ biomass). Two aquariums were used for the first injection exposure study (Bioassay 1), 6 for the waterborne/per os exposure study (Bioassay 2) and 2 for the second injection study (Bioassay 3 ) as outlined in Table 1. The aquariums were continuously aerated with a single airstone, covered to prevent animal escape and a $90 \%$ water exchange performed each morning. Bacteriaexposed aquariums were maintained in a room separate from the negative control aquariums so as to min- imize the possibility of cross-contamination. A mean water temperature of $28^{\circ} \mathrm{C}$ was maintained in both bioassay rooms during the 3 studies through placement of continuously operating electric area heaters. All shrimp were fed a pelleted ration (Ziegler No. 4 pellet) ad libitum once daily during the studies. The only exceptions were the per os-exposed treatment shrimp and a corresponding per os negative control group (described below).

Bioassay 1. Injection exposure to the Streptococcus-like isolate. The bacterial isolate used in this bioassay was cultured from the lymphoid organ of a naturally infected Farm A Litopenaeus vannamei and stored at $-80^{\circ} \mathrm{C}$ in Brucella broth with glycerol (Cryosaver $^{\mathrm{TM}}$ tube). The bacteria was later thawed, streaked and aerobically cultured on BA for $18 \mathrm{~h}$ at $28^{\circ} \mathrm{C}$ and a colony then transferred to $50 \mathrm{ml}$ of tryptose broth. Following $18 \mathrm{~h}$ incubation with agitation (28 to $30^{\circ} \mathrm{C}$ ), the bacterial suspension was pelleted by centrifugation $\left(2080 \times g, 30 \mathrm{~min}, 4^{\circ} \mathrm{C}\right)$, the supernatant discarded and the pellet suspended in sterile $2 \%$ saline to achieve a turbidity equivalent to a McFarland No. 2 standard (a concentration of $\sim 600 \times 10^{6}$ colony forming units [CFU] $\mathrm{ml}^{-1}$ ). A $10 \mu$ aliquot was then transferred to a $15 \mathrm{ml}$ tube and diluted 1:1000 with $2 \%$ sterile saline to obtain a concentration of $\sim 6000 \mathrm{CFU} \mathrm{\mu l}^{-1}$. Six shrimp were then intramuscularly injected (IM) in the third abdominal segment with $\sim 50$ to $80 \mu \mathrm{l}$ of the bacterial dilution using a $1 \mathrm{ml}$ tuberculin syringe to achieve 3 to $5 \times 10^{5} \mathrm{CFU}$ shrimp $^{-1}$, similar to dosages used in past Vibrio sp. infectivity studies (Saulnier et al. 2000). To serve as negative controls, 6 shrimp were similarly injected with sterile 
$2 \%$ saline. Moribund and freshly dead (i.e. no muscle opacity or difference in color from live shrimp observed) shrimp were collected, the needle of a $1 \mathrm{ml}$ tuberculin syringe inserted into the base of the fourth periopod and $\sim 50$ to $100 \mu$ of hemolymph extracted from the ventral sinus. Hemolymph samples (1 or 2 drops sample $\mathrm{e}^{-1}$ ) were immediately streaked on BA plates and observed for growth after 18 to $24 \mathrm{~h}$ aerobic incubation $\left(28^{\circ} \mathrm{C}\right)$. One representative colony per plate was Gram-stained and observed by light microscopy to confirm the presence of Gram-positive cocci. Finally, 3 representative colonies from a single plate were randomly selected, streaked onto $3 \mathrm{BA}$ slants, and incubated for $24 \mathrm{~h}\left(28^{\circ} \mathrm{C}\right)$. The slants were then filled with sterile mineral oil and stored at room temperature until used in Bioassay 2. The bioassay was terminated on Day 3 when the last bacteriainjected shrimp was collected in a moribund state.

Bioassay 2. Waterborne and per os exposures to the Streptococcus-like isolate. Six 10 gal aquariums containing 5 SPF Litopenaeus vannamei juveniles each were utilized (Table 1). Two aquaria were designated as replicate per os treatment groups and 2 aquariums as replicate waterborne treatment groups. The remaining 2 aquariums were placed in a separate room to prevent the possibility of bacterial contamination and served as per os and waterborne negative control tanks. Waterborne and per os exposures to the Streptococcus-like isolate were conducted each morning during the first $5 \mathrm{~d}$ of this $12 \mathrm{~d}$ study following the daily water exchange. All moribund and freshly dead shrimp were bled for bacterial culture as described in Bioassay 1 and preserved for histologic analysis (see 'Materials and methods: Histopathology'). Streptococcus-like bacteria recovered from the hemolymph of 2 moribund per os-exposed shrimp and 2 waterborneexposed shrimp were analyzed using the API 20 Strep kit to confirm that the isolates were the same and equivalent to the original wild type isolate used in Bioassay 1.

Bacterial culture and shrimp exposure methods: A 11 sterile flask containing $400 \mathrm{ml}$ of tryptose broth was inoculated each evening with the bacterial isolate recovered during Bioassay 1 and the culture aerobically incubated with continuous agitation at 28 to $30^{\circ} \mathrm{C}$ overnight (18 to $20 \mathrm{~h}$ ). The culture was then equally divided between eight $50 \mathrm{ml}$ centrifuge tubes, the bacteria pelleted by centrifugation $\left(2060 \times g, 30 \mathrm{~min}, 4^{\circ} \mathrm{C}\right)$ and the supernatant removed using a disposable pipette. The bacterial pellets from 6 tubes were individually re-suspended in $50 \mathrm{ml}$ of artificial seawater by mixing and $150 \mathrm{ml}$ of bacterial suspension (3 tubes) added to each of the 2 waterborne treatment tanks. The bacterial pellets in the remaining 2 tubes were each re-suspended in $15 \mathrm{ml}$ of artificial seawater, the suspensions transferred into 2 medium size plastic weighing dishes and feed pellets (Ziegler No. 4 pellet) equivalent to $5 \%$ of the biomass $(2 \mathrm{~g})$ aquarium $^{-1}$ added. After $30 \mathrm{~s}$ the hydrated pellets were fed to the 2 per os treatment groups together with the excess bacterial suspension. Similarly, $2 \mathrm{~g}$ of pelleted feed was hydrated with artificial seawater and fed to the per os negative control group.

Bacterial counts: Water samples (50 $\mathrm{ml}_{\text {aquarium }}{ }^{-1}$ ) were collected from the 2 waterborne treatment tanks and corresponding negative control tank $\sim 30 \mathrm{~min}$ post-inoculation each day during the first $4 \mathrm{~d}$ of this $12 \mathrm{~d}$ study. Three serial tenfold dilutions were prepared from each water sample (1:1000 to 1:100 000) and $100 \mu \mathrm{l}$ streaked on BA plates using a bacterial cell spreader. An undiluted $100 \mu \mathrm{l}$ water sample from the negative control tank was similarly plated. Following 18 to $24 \mathrm{~h}$ aerobic incubation $\left(28^{\circ} \mathrm{C}\right)$, Streptococcus-like colonies were counted and CFUs $\mathrm{ml}^{-1}$ determined.

Bioassay 3. Freeze-thaw effects on the Streptococcus-like isolate. A total of 10 SPF Litopenaeus vannamei juvenile shrimp were intramuscularly injected with the same Streptococcus-like isolate used in Bioassay 2 . Injections were performed following the protocol described in Bioassay 1 and the shrimp then equally divided between two 10 gal aquariums as previously described. Resulting moribund and dead shrimp ( $\mathrm{n}=$ 10) were collected, equally divided into 2 groups and individually frozen in Whirl-pak ${ }^{\mathrm{TM}}$ bags (Nasco) at either $-80^{\circ} \mathrm{C}(\mathrm{n}=5)$ or $-20^{\circ} \mathrm{C}(\mathrm{n}=5)$. Four days postfreezing, all shrimp were thawed at room temperature for $60 \mathrm{~min}$, the head and first tail segment swabbed with $70 \%$ ethanol, and the abdomen aseptically severed from the head, cutting ventral to dorsal using a new sterile scalpel blade for each shrimp. A sterile disposable loop was inserted into the ventral sinus area of the first tail segment and aseptically extracted fluid then plated on BA. The shrimp were then returned to their respective freezers and the BA plates incubated overnight at $28^{\circ} \mathrm{C}$. Each plate was examined the next morning for the presence of Streptococcus-like colonies, which were Gram-stained and examined microscopically for the presence of Gram-positive cocci. Thawing and plating of the shrimp samples was repeated once per day over the next $2 \mathrm{~d}$ and then again at 30 and $60 \mathrm{~d}$ post-collection for a total of 5 freezethaw cycles.

Histopathology. Upon receipt of the juvenile SPF Litopenaeus vannamei population used in the 3 bioassays, 5 shrimp were preserved with Davidson's AFA and paraffin-embedded tissues were prepared for routine $H \& E$ histological analysis according to the methods of Bell \& Lightner (1988) in order to confirm their disease-free status. During Bioassays 1 and 2 all 
moribund and fresh dead shrimp from the negative control and treatment groups were bled for bacterial culture as previously described and then preserved with Davidson's AFA for histological analysis following standard methods. Upon terminating Bioassay 2, all surviving negative control and bacteria-exposed shrimp were similarly preserved. Streptococcus lesion severity was graded on a scale from 0 to 4 similar to that for scoring Taura syndrome virus (TSV)-induced lesions (Hasson et al. 1995). Streptococcus-induced lesions were defined as foci containing single or multiple, variably sized aggregates of vacuolated presumptive hemocytes with intravacuolar and extracellular cocci, and varying degrees of melanization. Complete absence of such lesions was graded as 0 , lesions in $<25 \%$ of an infected tissue was graded as 1 , lesions in 25 to $50 \%$ of a tissue graded as 2, lesions in 50 to $75 \%$ of a tissue graded as 3 and lesions in $>75 \%$ of a tissue graded as 4 . As these lesions were typically present in multiple tissues, a lesion severity grade was assigned to a given sample based on the single most severely affected tissue or organ. To better visualize the bacteria in the affected tissue, select sample blocks were re-cut and the sections Gram-stained according to Carson (1997) together with positive control tissue samples containing Gram-positive and negative organisms.

\section{RESULTS}

\section{Bacterial identification}

Small circular non-hemolytic white bacterial colonies ( 0.3 to $0.5 \mathrm{~mm}$ diameter), suggestive of a Streptococcus sp., were observed on BA plates from 1 of 6 shrimp from each farm and from both pooled hemolymph samples within $24 \mathrm{~h}$ post-inoculation. The colonies grew both aerobically and anaerobically and consisted of non-motile, Gram-positive cocci that were both oxidase- and catalase-negative. Wet mount analysis of tryptose broth-cultured bacteria revealed numerous chains consisting of 5 to 8 cocci, characteristic of streptococci. Analysis of the isolate by the API 20 Strep kit characterized the bacteria as $99.9 \%$ similar to S. uberis (API Code 7463713). In contrast, the Omnilog system identified the isolate as $S$. parauberis. PCR analysis of the DNA extracted from the Farm A isolate, Farm B isolate, Bioassay 2 isolate and ATCC $S$. porcinus isolate using a universal Streptococcus genus-specific primer set resulted in amplification of a $207 \mathrm{bp}$ band for each of the 4 samples (Fig. 1). This confirmed that the 2 farm wild type isolates and the isolate recovered from Bioassay 2 were members of the streptococci.

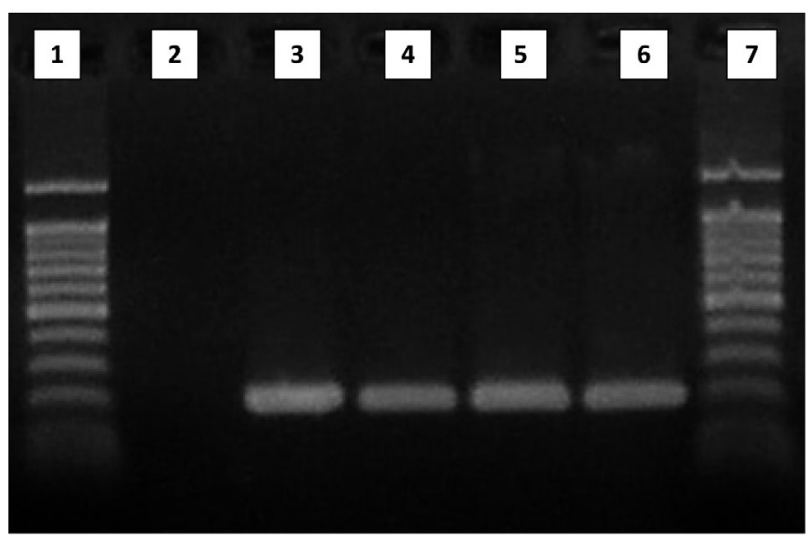

Fig. 1. Electrophoresis banding patterns of 4 Streptococcus spp. following PCR using a universal primer set that amplifies a unique 207 bp region within the streptococcal 16S rDNA gene. Lanes 1 and 7: $1 \mathrm{~kb}$ ladder; Lane 2: negative control water template; Lane 3: Farm A Streptococcus-like isolate; Lane 4: Farm B Streptococcus-like isolate; Lane 5: Streptococcuslike isolate recovered from moribund Bioassay 2 treatment shrimp; Lane 6: ATCC S. porcinus isolate

\section{Bioassay 1. Isolate injection}

The primary objectives of this study were to verify the pathogenicity of the Streptococcus-like isolate, reisolate the organism for subsequent use in Bioassay 2 and to perform histology on moribund treatment shrimp. Injection of 6 SPF Litopenaeus vannamei juveniles with the Farm A Streptococcus isolate resulted in $100 \%$ cumulative mortality within $3 \mathrm{~d}$ post-injection compared to $17 \%$ mortality among the corresponding negative control shrimp (Fig. 2). Five of the 6 treatment shrimp were collected moribund or freshly dead. The

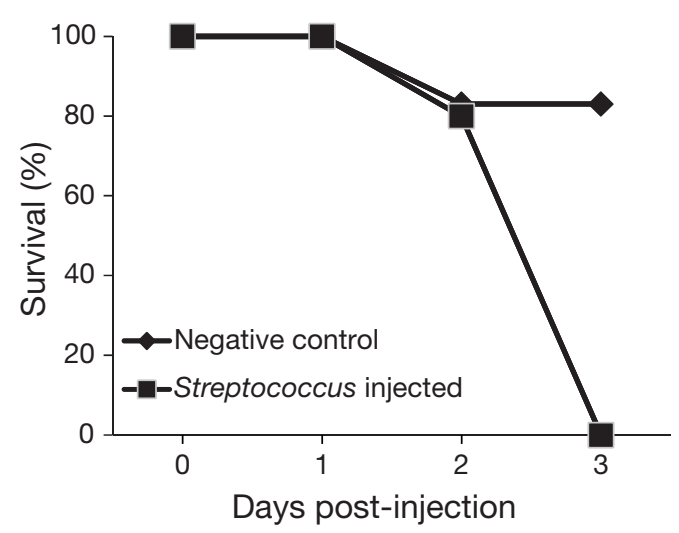

Fig. 2. Litopenaeus vannamei. Daily percent survival of Bioassay 1 juvenile shrimp injected with either a saline suspension containing a Streptococcus-like bacterial isolate or $2 \%$ sterile saline to serve as a negative control. Survival among the bacteria-injected treatment group was $0 \%$ within $3 \mathrm{~d}$ post-injection versus $83 \%$ survival among the negative control group 
sixth shrimp was found severely degraded and was discarded. Moribund treatment shrimp were lethargic and assumed a laterally recumbent position prior to death with no other grossly observable clinical signs. Chromatophore expansion with consequent darkening of the body and/or reddening of the appendages was notably absent from the infected individuals. Prior to preservation with Davidson's fixative, each of the 5 treatment shrimp were bled and the samples plated on BA. All 5 cultures produced Streptococcus sp. colonies of Gram-positive cocci within $18 \mathrm{~h}$ post-inoculation that were morphologically identical to those cultured from the original farmed shrimp and hemolymph samples. One isolate was selected, cultured on 3 blood agar slants and stored for use in Bioassay 2. Some colonies that were morphologically different from the Streptococcus sp. colonies were also cultured from 2 treated shrimp samples that had been bled postmortem. These colonies were in low numbers compared to the Streptococcus sp., consisted of Gram-negative rods and were considered to be postmortem contaminants. The single negative control shrimp that died during the study was preserved for histological analysis, but not bled for bacterial culture.

\section{Bioassay 2}

Waterborne and per os exposures

Mortality among the replicate waterborne-exposed treatment groups began on Days 4 and 5 and resulted in $80 \%$ mortality in one group and $100 \%$ in the second during this $12 \mathrm{~d}$ study (Fig. 3). Mortality among the replicate per os-exposed shrimp began on Days 6 and 7 with cumulative mortalities of 40 and $100 \%$. No mortality occurred among the waterborne or per osexposed negative control groups. Similar to the injection study treatment shrimp, the principal clinical signs of disease included lethargy and lateral recumbence just prior to death. A total of 8 waterborne-exposed and 7 per os-exposed treatment shrimp were collected moribund or recently dead. During extraction of hemolymph from these shrimp for bacterial culture it was noted that many of the samples failed to clot after several minutes and were markedly white and turbid (Fig. 4). Microscopic examinations of wet mount and Gram-stained samples demonstrated that the white coloration was due to the presence of numerous Grampositive cocci. BA cultures of the 15 hemolymph samples resulted in the growth of numerous Streptococcus sp. colonies on each plate within $18 \mathrm{~h}$ post-inoculation and wet-mount analysis confirmed the presence of cocci in each sample. API 20 Strep analysis of individual bacterial isolates recovered from 2 moribund

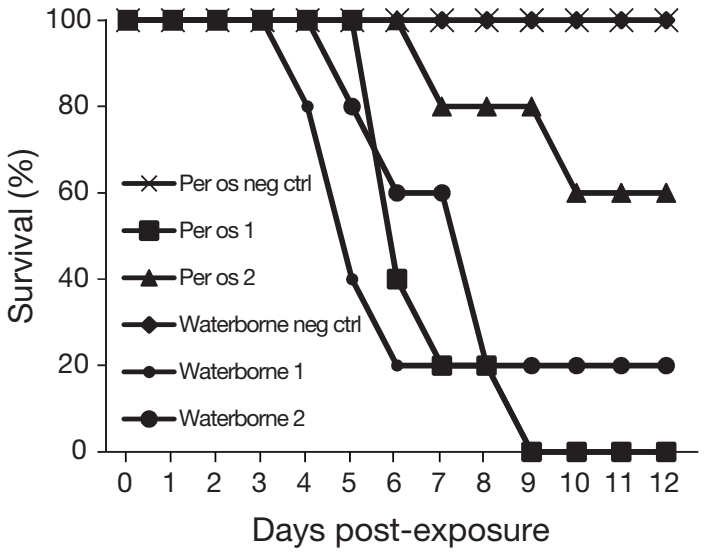

Fig. 3. Litopenaeus vannamei. Daily percent survival of Bioassay 2 juvenile shrimp following waterborne and per os exposures to a Streptococcus-like bacterial isolate. Bacterial treatments were performed in duplicate during the first $5 \mathrm{~d}$ of the study. Survivals among the 2 per os treatment groups were 0 and $60 \%$. Survivals among the 2 waterborne treatment groups were 0 and $20 \%$. No mortality occurred in either the waterborne or per os negative control (neg ctrl) groups

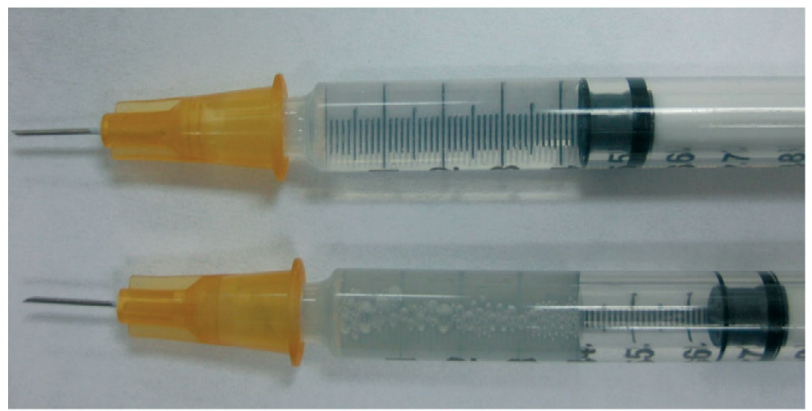

Fig. 4. Hemolymph from a moribund Litopenaeus vannamei juvenile that was per os exposed to a Streptococcus-like isolate (Bioassay 2) appears white and opaque when first drawn (bottom syringe) instead of clear and translucent as seen in healthy shrimp (similar to the water sample in the top syringe). Note that the gradations on bottom syringe are not visible due to sample opacity, which is caused by the presence of numerous Streptococcus cocci. The dark coloration of the sample is normal, occurred within 1 to 2 min after collection and is due to oxidation of hemocyanin in the hemolymph (Dawson \& Mallette 1945)

waterborne and 2 moribund per os treatment shrimp produced the same code for all 4 isolates (API 7463713) and identified them as $S$. uberis.

Bacterial counts of waterborne treatment aquariums

Distinct non-hemolytic Streptococcus sp. colonies grew on all of the plates inoculated with waterborne treatment tank water and no other colony types were observed. Colony counting was done using the BA plates inoculated with the $10^{-5}$ water sample dilutions. 
Streptococcus sp. colony counts of the 2 waterborneexposed tanks ranged from $0.2 \times 10^{6}$ to $14 \times 10^{6} \mathrm{CFU}$ $\mathrm{ml}^{-1}$ with a mean range of $\sim 5.5$ to $6 \times 10^{6} \mathrm{CFU} \mathrm{ml}{ }^{-1}$ (Table 2). Bacteria counts were not performed on Day 5 when the last waterborne exposure was performed. The counts on Days 0 and 1 were considerably lower than the subsequent counts as marine broth was erroneously used to produce the first 2 cultures. All subsequent cultures were conducted using tryptose broth, which resulted in 10 -fold higher bacterial counts. No Streptococcus sp. colonies were cultured from the corresponding negative control group water samples.

\section{Histopathology}

No viral or bacterial infections were detected by routine histology in the 5 SPF Litopenaeus vannamei test shrimp that were preserved upon arrival at TVMDL or in the single dead negative control shrimp collected during Bioassay 1 (Table 3). The cause of death of this control shrimp collected on Day 2 of that study could not be determined by histology, but was possibly due to molt-induced stress. Upon terminating Bioassay 2 on Day 12, 4 surviving per os-negative control shrimp, 3 surviving per os treatment shrimp and 1 waterborne treatment shrimp were collected and analyzed by routine histology. One of the 3 per os-exposed samples was found to have low numbers (Severity Grade 1) of cocci within the lymphoid organ (LO), whereas no infections or lesions were detected in the remaining 7 samples.

Fresh dead or moribund shrimp from the injection treatment group of Bioassay $1(\mathrm{n}=5)$, per os treatment group of Bioassay $2(\mathrm{n}=7)$ and waterborne treatment group of Bioassay $2(\mathrm{n}=8)$ were analyzed by routine

Table 2. Daily bacterial counts (colony-forming units [CFU] $\mathrm{ml}^{-1}$ ) of tank water from Bioassay 2 treatment tanks (Tanks 5 and 6 ) subjected to waterborne Streptococcus sp. exposure. No Streptococcus sp. colonies were cultured from the negative control group water samples. NA: not analyzed

\begin{tabular}{|lcccrrr|r}
\hline Tank no. & Day 0 & Day 1 & Day 2 & Day 3 & Day 4 & Day 5 & Mean CFU ml $^{-1}$ \\
\hline 5 & $0.2 \times 10^{6}$ & $0.3 \times 10^{6}$ & $14 \times 10^{6}$ & $6 \times 10^{6}$ & $9 \times 10^{6}$ & NA & $6 \times 10^{6}$ \\
6 & $0.2 \times 10^{5}$ & $0.2 \times 10^{6}$ & $6 \times 10^{6}$ & $10 \times 10^{6}$ & $11 \times 10^{6}$ & NA & $5.5 \times 10^{6}$ \\
\hline
\end{tabular}

Table 3. Litopenaeus vannamei. Histologic findings of Bioassays 1 and 2 summarizing the number of shrimp per treatment analyzed by histology, day of collection, the number with Streptococcus infections, overall lesion severity grade and the cumulative percent mortality upon termination on Day 3 (Bioassay 1) or Day 12 (Bioassay 2). Test shrimp were exposed to a Streptococcus sp. isolate via injection in Bioassay 1 and by waterborne and per os routes in Bioassay 2. Lesion severity grade (G) is based on a scale from 1 to $4: 1=$ mild focal to multifocal lesions in $<25 \%$ of the affected tissue, $4=$ severe multifocal to diffuse lesions in $>75 \%$ of an affected tissue. NA: not analyzed; ND: not detected

\begin{tabular}{|c|c|c|c|c|c|c|c|c|}
\hline \multirow{2}{*}{$\begin{array}{c}\text { Tank } \\
\text { no. }\end{array}$} & \multirow{2}{*}{ Treatment } & \multicolumn{4}{|c|}{ - Histology } & \multicolumn{2}{|c|}{ Streptococcus-positive } & \multirow{2}{*}{$\begin{array}{c}\text { Cumulative } \\
\text { mortality } \\
(\%)\end{array}$} \\
\hline & & $\begin{array}{c}\text { Day } \\
\text { sampled }\end{array}$ & $\begin{array}{l}\text { No. } \\
\text { examined }\end{array}$ & $\begin{array}{l}\text { Lesion } \\
\text { prevalence }\end{array}$ & $\begin{array}{l}\text { Lesion } \\
\text { severity }\end{array}$ & Haemolymph & API & \\
\hline \multicolumn{9}{|c|}{ Bioassay 1} \\
\hline \multirow[t]{2}{*}{1} & Injection negative ctrl & Arrival day & 5 & 0 of 5 & ND & NA & NA & $1 / 6(17)$ \\
\hline & & Day 2 & 1 & 0 of 1 & ND & NA & NA & \\
\hline \multirow[t]{2}{*}{2} & Injection Streptococcus & Day 2 & 1 & 1 of 1 & G4 & 1 of 1 & NA & $6 / 6(100)$ \\
\hline & & Day 3 & 4 & 4 of 4 & G3-4 & 4 of 4 & NA & \\
\hline \multicolumn{9}{|c|}{ Bioassay 2} \\
\hline 1 & Per os negative ctrl & - & 0 & NA & NA & NA & NA & $0 / 5(0)$ \\
\hline \multirow[t]{3}{*}{2} & Per os Streptococcus & Day 6 & 3 & 3 of 3 & G3 -4 & 3 of 3 & 2 of 2 & $5 / 5(100)$ \\
\hline & & Day 7 & 1 & 1 of 1 & G4 & 1 of 1 & NA & \\
\hline & & Day 9 & 1 & 1 of 1 & G4 & 1 of 1 & 1 of 1 & \\
\hline \multirow[t]{3}{*}{3} & Per os Streptococcus & Day 7 & 1 & 1 of 1 & G4 & 1 of 1 & NA & $2 / 5(40)$ \\
\hline & & Day 10 & 1 & 1 of 1 & G4 & 1 of 1 & NA & \\
\hline & & Day 12 & 3 & 1 of 3 & G1 & 0 of 3 & NA & \\
\hline 4 & Waterborne negative ctrl & Day 12 & 4 & 0 of 4 & ND & 0 of 4 & NA & $0 / 5(0)$ \\
\hline \multirow[t]{3}{*}{5} & Waterborne Streptococcus & Day 4 & 1 & 1 of 1 & G3 & 1 of 1 & NA & $5 / 5(100)$ \\
\hline & & Day 5 & 2 & 2 of 2 & G4 & 2 of 2 & 2 of 2 & \\
\hline & & Day 6 & 1 & 1 of 1 & G4 & 1 of 1 & NA & \\
\hline \multirow[t]{4}{*}{6} & Waterborne Streptococcus & Day 5 & 1 & 1 of 1 & G4 & 1 of 1 & NA & $4 / 5(80)$ \\
\hline & & Day 6 & 1 & 1 of 1 & G4 & 1 of 1 & NA & \\
\hline & & Day 8 & 2 & 2 of 2 & G3-4 & 2 of 2 & NA & \\
\hline & & Day 12 & 1 & 0 of 1 & ND & 0 of 1 & NA & \\
\hline
\end{tabular}


histology. Severe Grade 3 to 4 systemic bacterial infections were detected in all 20 samples (Table 3) with the LO being the most severely affected tissue. Both lesion morphology and distribution were found to be identical to those observed in naturally infected farmed
Litopenaeus vannamei. Normal LO sections contain numerous arterioles characterized by a thick wall surrounding an endothelial-lined lumen when viewed in cross-section (Fig. 5A). In contrast, the severely infected treatment shrimp of this study displayed a
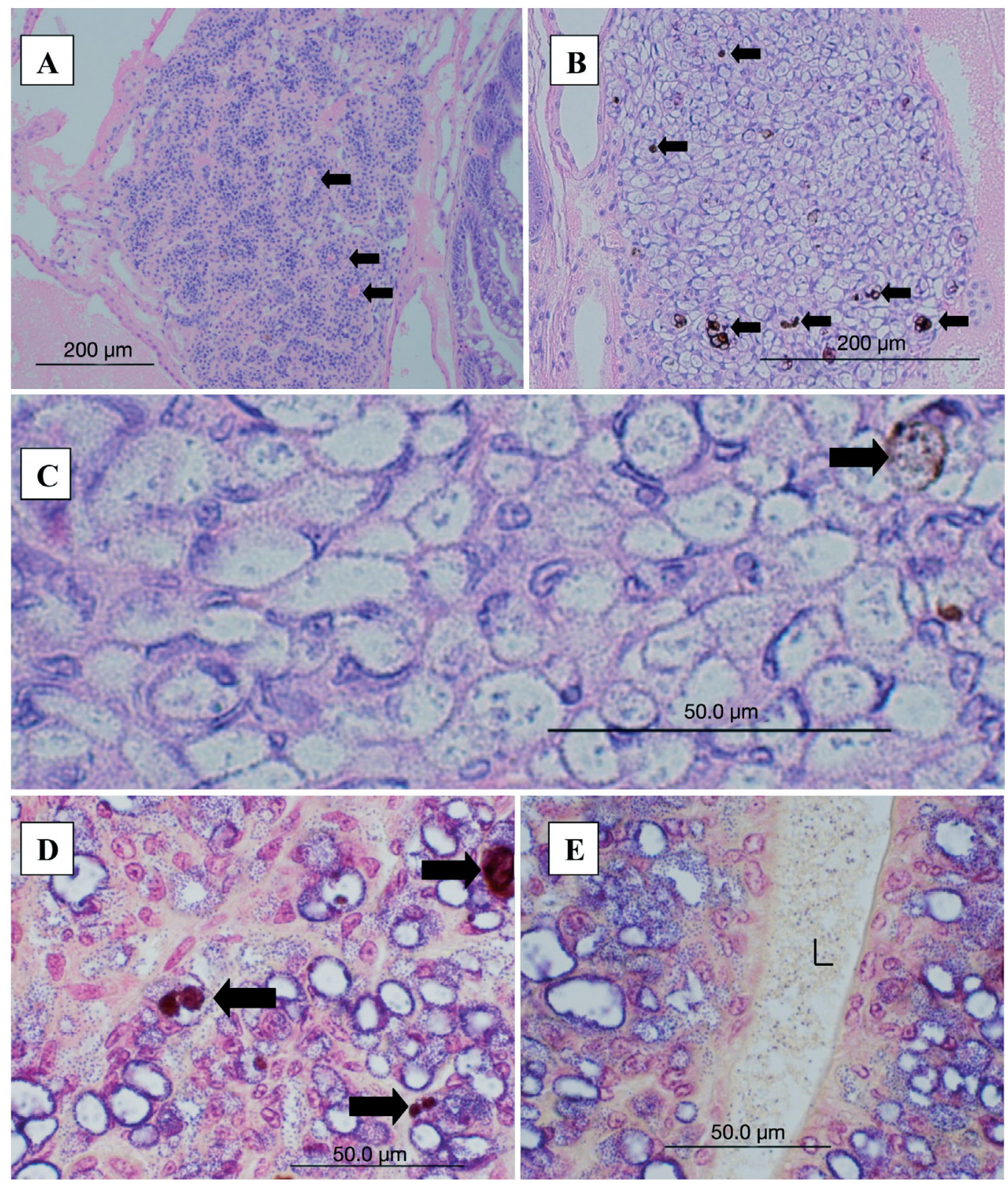

Fig. 5. Litopenaeus vannamei. Histological sections of naturally occurring and experimentally induced Streptococcus sp. infections within the lymphoid organ and subgastric artery. (A) Normal $L$. vannamei lymphoid organ showing individual arterioles in cross-section (arrows). H\&E stain. (B) Lymphoid organ of a L. vannamei with a naturally occurring Streptococcus sp. infection. Note the homogeneous and highly vacuolated appearance of the organ and loss of arteriole morphology. A few small melanized hemocytic nodules are present (arrows). H\&E stain. (C) High magnification view of lymphoid organ cells in (B); all of the cells are highly vacuolated. The fine stippling visible around the cells and lining the inner perimeter of the vacuoles are cocci. H\&E stain. (D) High magnification view of a section of lymphoid organ in a shrimp with an experimentally induced infection. Numerous minute cocci (blue spheres) are evident within the interstitium and the numerous cytoplasmic vacuoles that are present. Normal arteriole architecture is absent and a few melanized nodules are present (arrows). Gram stain. (E) Longitudinal section through the subgastric artery of a shrimp with an experimentally induced infection (Bioassay 2). Note the Gram-positive cocci within the arteriolar wall, vacuoles and lumen (L). Gram stain 
marked hemocytic vasculitis of the LO characterized by the replacement of normal arterioles with a solid homogeneous field of numerous vacuolated hemocytes. These cells typically contained a large cytoplasmic vacuole lined with cocci and a marginated or acentric nucleus. Numerous extracellular cocci admixed with low numbers of small melanized hemocytic nodules were typically present (Fig. 5B-D) and individual arterioles could not be distinguished. The general morphology of the arterioles in moderately infected shrimp was distnguishable (i.e. walls and lumen) and contained a lower number of cocci-laden vacuolated cells, small hemocytic nodules and extracellular cocci as compared to the severe cases. Numerous cocci were also visible within the hemal sinuses surrounding the LO arterioles. Similar histologic changes and bacterial distribution were also present in the walls of the subgastric artery (Fig. 5E) and, to a much lesser degree, in all of the other affected tissues. Following the LO in terms of infection severity were the gills (Fig. 6A,B) and heart (Fig. 6C); the interfascicular spaces of the skeletal muscle of the cephalothorax, abdomen and appendages (Fig. 6D); and the submucosal connective tissue or muscle of the esophagus (Fig. 6E), stomachs, midgut (Fig. 7A) and hindgut. Rare to infrequent scattered vacuolated hemocytic nodules and varying numbers of cocci were found in the hemal sinuses or vessels associated with the hematopoietic tissue (Fig. 7B), hepatopancreas (Fig. 7C) and antennal gland (Fig. 7D) as well as the connective tissues of the anterior and posterior midgut ceca (Fig. 7E) and in the nerve cord (Fig. 7F). In all cases, the bacteria were very difficult to detect by routine H\&E histology (Fig. 5C) because of their small diameter $(\sim 0.8 \mu \mathrm{m}$ diameter $)$ and light basophilia, providing little contrast with the surrounding tissues. In Gram-stained tissue sections the bacteria stain dark blue to purple and are easily visualized by light microscopy (Figs. 5D,E, 6 \& 7).

\section{Bioassay 3. Freeze-thaw effects on the Streptococcus isolate}

As in Bioassay 1, all 10 treatment shrimp of Bioassay 3 died or were collected moribund within $3 \mathrm{~d}$ post-injection (PI) and were then divided into 2 groups of 5 shrimp each, one group frozen at $-20^{\circ} \mathrm{C}$ and the other at $-80^{\circ} \mathrm{C}$. Both groups of shrimp were thawed, the ventral sinus fluid plated on BA and the shrimp re-frozen on 3 successive days beginning $4 \mathrm{~d}$ post-collection and, again, on Days 30 and 60 for a total of 5 freeze-thaw cycles. Small circular white Streptococcus-like colonies too numerous to count, identical to those observed throughout this study, grew on all BA plates up through and including all those prepared after thawing the 10 shrimp for the fifth time. Colony numbers and morphology were virtually identical in the cultures of the shrimp stored at both -20 and $-80^{\circ} \mathrm{C}$. Microscopic analysis of Gramstained preparations of representative colonies removed from each plate confirmed the presence of Gram-positive cocci in each sample.

\section{DISCUSSION}

Histologic analyses of farmed Litopenaeus vannamei juveniles in September 2008 demonstrated the presence of unique changes in the LO associated with a systemic infection by a presumptive Streptococcus sp. Numerous cocci were observed within the hemolymph in virtually all of the tissues throughout the shrimp by routine histology together with a comparatively mild inflammatory response on the part of the host as suggested by the lack of melanized lesions. The bacterial agent was subsequently isolated from fresh L. vannamei tissue and hemolymph samples originating from 2 separate farms that had been affected by a persistent chronic shrimp mortality problem. Based on the preliminary biochemical characterization work conducted in this study, the bacterial isolate was found to be a non-hemolytic, non-motile, oxidase- and catalasenegative, Lancefield Group B, Gram-positive coccus, which reacted positively with universal streptococcal PCR primers. Although analyses of the isolate using the API Strep 20 kit and Biolog system produced conflicting species identifications (S. uberis vs. S. parauberis), the overall findings definitively indicate that the isolate is a member of the Streptococcus genus. Historically, differentiation of these 2 streptococcal species is difficult phenotypically with $S$. parauberis classified as $S$. uberis type II in the past (Jayarao et al. 1991). Final speciation of the isolate through genotypic analysis was beyond the scope of the current investigation and is the focus of an ongoing study.

Injection of SPF Litopenaeus vannamei juveniles with an inoculum containing the Streptococcus sp. isolate (Bioassay 1) resulted in 100\% mortality within $3 \mathrm{~d}$ PI and produced histologic lesions in all 5 examined treatment shrimp that were identical to those observed in $L$. vannamei with a naturally occurring infection. The isolate was successfully recovered and a pure culture obtained for use in the subsequent bioassay. The results of Bioassay 2 demonstrated that SPF L. vannamei test shrimp can be infected by the agent via water- and feed-borne routes with cumulative mortalities of $80-100$ and $40-100 \%$, respectively, within a $12 \mathrm{~d}$ period. Waterborne bacterial concentrations of $\sim 10^{6} \mathrm{CFU} \mathrm{ml} \mathrm{m}^{-1}$ or more, as reported in Vibrio sp. infectivity studies (Saulnier et al. 2000), were sufficient to 

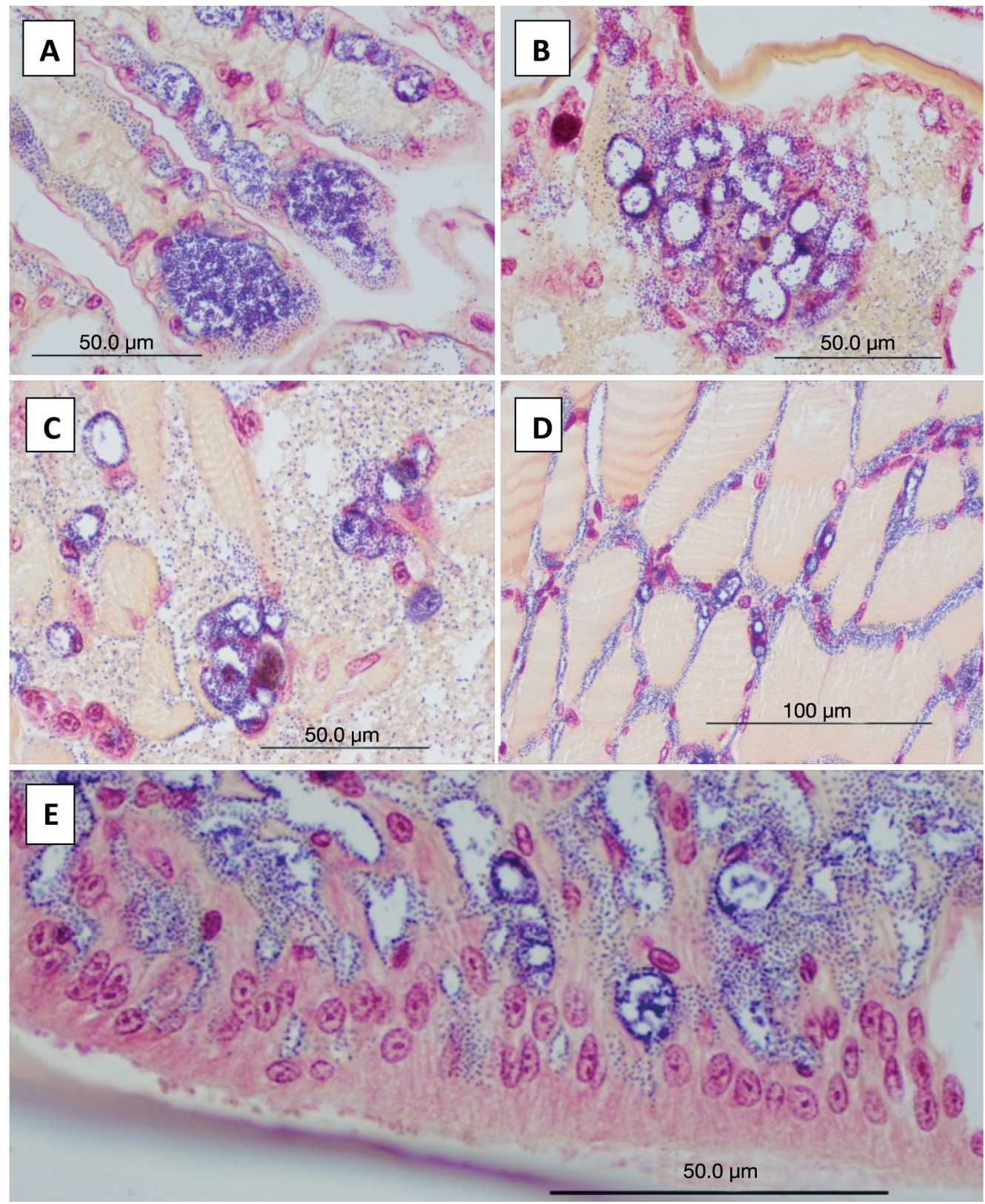

Fig. 6. Litopenaeus vannamei. Gram-stained histological sections of tissues that show moderate to severe changes in shrimp with experimentally induced Streptococcus sp. infections. (A) Secondary gill lamellae with numerous intravascular cocci. (B) Artery in the primary gill lamellae with a large hemocytic aggregate containing numerous cocci. (C) Myocardium with numerous cocci free in the hemolymph and 2 hemocytic aggregates. (D) Skeletal muscle with numerous interfascicular cocci and a few vacuolated hemocytes. (E) Esophagus with numerous extracellular cocci and a few bacteria-laden vacuolated cells within the submucosal connective tissue

induce streptococcosis in the test shrimp. Similar to Bioassay 1, the histological findings of 15 treatment shrimp from Bioassay 2 demonstrated that per os and waterborne exposure to the Streptococcus sp. isolate caused a bacteremia and histologic changes identical to those seen in naturally infected farmed shrimp. Further, a pure culture of the isolate was again obtained from the experimentally infected test shrimp and found to be morphologically and biochemically identical to the original wild type isolate. The successful induction of the disease by 3 different routes of exposure and subsequent recovery of the causative agent fulfill the criteria of Koch's postulates (Koch 1884) for this bacterium, establishing it as the cause of the first reported case of streptococcosis in marine penaeid shrimp in the Western Hemisphere. 

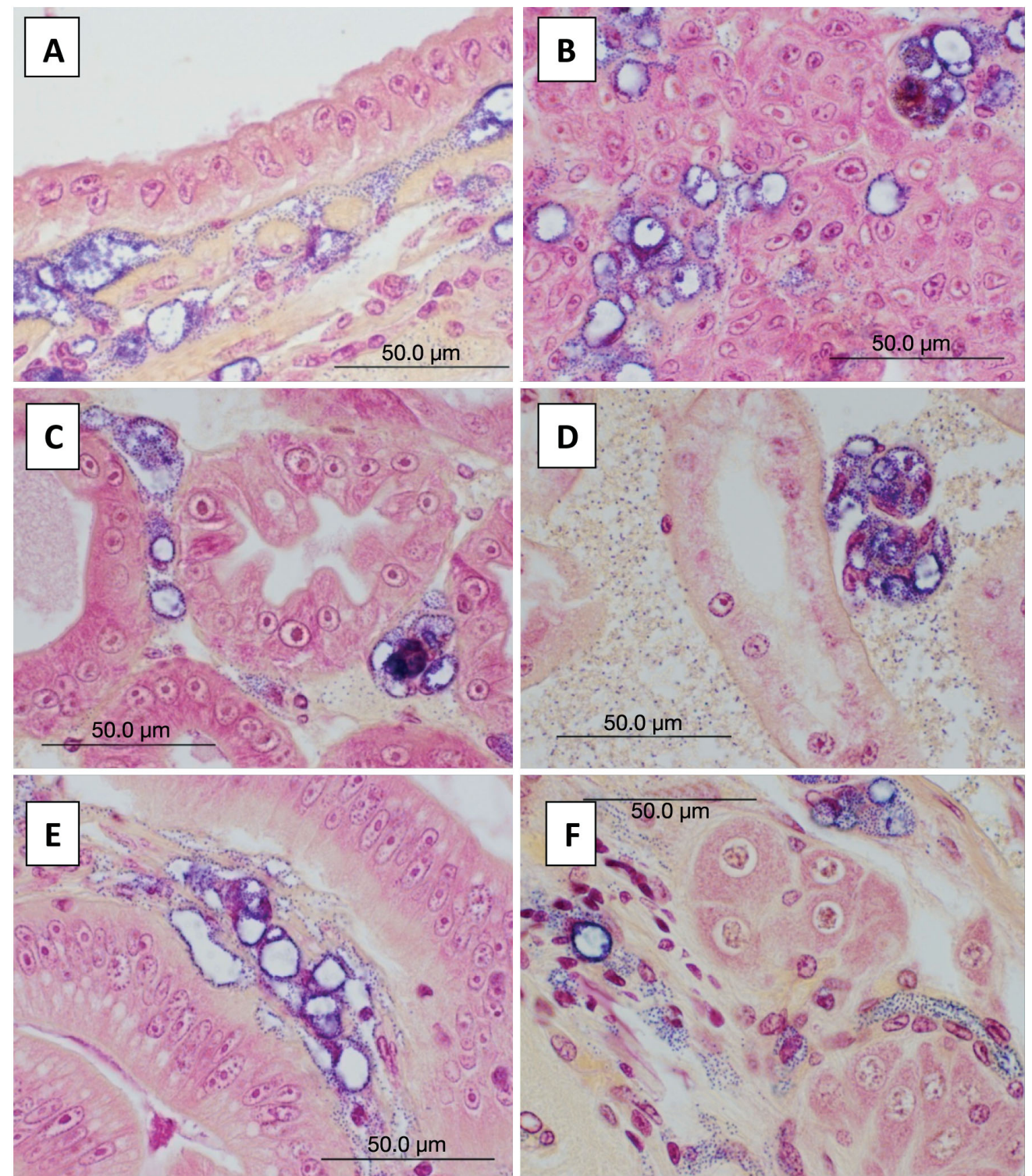

Fig. 7. Litopenaeus vannamei. Gram-stained histological sections of various tissues demonstrating extracellular and intravacoular Gram-positive cocci in shrimp with an experimentally induced Streptococcus sp. infection. (A) Midgut submucosa, (B) hematopoietic tissue, (C) hepatopancreatic hemal sinuses, (D) antennal gland hemal sinus, (E) anterior midgut cecum connective tissue, and (F) neurosecretory cells of a segmental ganglion in the ventral nerve cord

The only shrimp disease currently reported in the literature that is similar to our findings is 'white muscle disease' (WMD) of Macrobrachium rosenbergii, which is caused by 2 different Lactococcus spp. (Wang et al. 2008). Cheng \& Chen (1998) demonstrated that injection-mediated infections of freshwater prawns with the WMD agent resulted in $100 \%$ mortality $11 \mathrm{~d}$ PI. However, as the dose injected was not specified, we cannot compare the pathogenicity of this disease with Streptococcus sp. infection in Litopenaeus vannamei. Histologic analysis of the experimentally infected $M$. rosenbergii was limited to the hepatopancreas and skeletal muscle. The reported inflammatory response was somewhat similar to that of our L. vannamei samples in terms of finding melanized hemocytic nodules within the hemal sinuses of the hepatopancreas and hemocytic infiltrates in the skeletal musculature, but analysis of additional $M$. rosenbergii tissues would be needed to make a complete comparison. Interestingly, both bacterial isolates induced opaque or 'milky' white hemolymph in their respective shrimp hosts as a result of the high concentration of circulating bacteria. In light of the lack of other overt clinical signs of disease in infected L. vannamei, this finding, together with 
microscopic verification of numerous Gram-positive cocci within a given hemolymph sample, may serve as valuable diagnostic tools for making a rapid presumptive diagnosis of streptococcosis in the field.

The histologic changes caused by this disease in the LO, together with the widespread distribution of cocci throughout the tissues, are unique in penaeids, not previously reported and can be used to make a definitive diagnosis of streptococcosis in Gram-stained sections. Unlike the formation of LO spheroids following the sequestration of various shrimp viruses and other small antigenic agents by hemocytes (Hasson et al. 1999) or the hemocytic encapsulation of bacteria forming melanized nodules within the LO and other vascularized tissues as seen with a systemic vibriosis (Lightner 1996), streptococcosis in L. vannamei induces a distinctive vasculitis in the LO. The disease is characterized by the presence of cocci-containing cytoplasmic vacuoles (phagosomes) in numerous presumptive hemocytes together with low numbers of small interstitial melanized hemocytic nodules. In severe infections, normal LO arteriole morphology is lost and replaced by vacuolated, bacteria-laden cells (Fig. 5). These cells appear to progressively increase in number within the walls of the arterioles, spreading into the arteriole lumens and surrounding hemal sinuses until individual arterioles are no longer discernable by light microscopy and replaced by a solid field of vacuolated cells (Fig. 5B,C). These changes may be considered the histologic hallmark of this disease and suggest that the bacteria are either successfully phagocytized and sequestered by these presumed hemocytes or the hemocytes are actively invaded by the bacteria as has been demonstrated to occur in some mammalian epithelial cell lines following experimental exposure to Group B Streptococci (Rubens et al. 1992, Almeida \& Oliver 1995). Once in the phagosome the cocci may continue replicating, leading to eventual cell lysis and the release of bacterial progeny into surrounding tissues. Another possibility is that the bacteria simply use the phagosome as a safe haven where they are protected from host immune responses and exposure to antimicrobials without replicating. Zlotkin et al. (2003) reported a similar phenomenon in salmonid phagocytes exposed to $S$. iniae. Dubbed the 'Trojan horse effect', these investigators demonstrated that phagocytized $S$. iniae not only survive in fish macrophages, but induce apoptosis of these cells, effectively minimizing the host immune response while being transported and delivered to typically inaccessible regions such as the central nervous system. Ultrastructural analysis of infected LO cells in time course-sampled shrimp, together with an assessment of their apoptotic index, are needed to determine if the mode of entry and occurrences reported in Streptococcus-infected fish phagocytes or mammalian epithelial cells are comparable to those in Streptococcus-infected shrimp hemocytes.

Prevention and treatment of this new bacterial disease has already proved difficult for the farmers confronting this problem. The intracellular location of the agent will influence the development of management strategies for treating this disease. Antibiogram results indicated the isolate to be susceptible to a variety of antibiotics including oxytetracycline (OTC) (P. W. Varner \& K. W. Hasson unpubl. data). However, addition of OTC-medicated feed to affected ponds did not end the mortalities. We speculate that the intracellular location of the organism may shield it against antimicrobials like OTC, making treatment of already infected shrimp ineffectual. This is similar to the problem of treating necrotizing hepatopancreatitis (NHP), an intracellular rickettsial-like disease of Litopenaeus vannamei (Frelier et al. 1992). Successful prevention of NHP has been achieved through the rapid application of OTC-medicated feed at the first signs of an outbreak while the shrimp are still feeding (Brock \& Main 1994) and may be a strategy worth testing in Streptococcusaffected regions. However, the threat of inducing OTC-resistant Streptococcus sp. is a concern, particularly in regions already using this antibiotic to combat NHP. Another strategy employed by farmers is to reduce bacterial disease susceptibility in their stocks by minimizing stressful environmental culture conditions based on the premise that the Streptococcus sp. responsible is an opportunistic pathogen and outbreaks are stress-related. This was attempted by reducing stocking densities, increasing water exchanges and through early harvests with mixed results reported. Low dissolved oxygen concentration has been reported to increase the virulence and distribution of Enterococcus seriolicida disease in yellowtail Seriola quinqueradiata (Vendrell et al. 2006). Nighttime dissolved oxygen (DO) lows of 2.5 to $3.5 \mathrm{ppm}$ were reported in the affected shrimp farms and continuous aeration at night should be tested to determine if avoidance of suboptimal DO concentrations may improve survivals in Streptococcus-infected shrimp ponds. Other efforts have been focused on finding and eliminating the source of the disease. However, elimination of this bacteria through farm dry outs may prove difficult as it has been demonstrated experimentally that $S$. parauberis isolates from cattle and turbot can endure for $1 \mathrm{mo}$ in saltwater and up to 6 mo in marine sediment by entering into a dormant state in order to persist for longer periods in the marine environment. These viable yet non-culturable bacteria can be present in high numbers in the environment, but are not detectable via normal direct plate count methods (Currás et al. 2002). This trait, combined with the fact that 
many streptococcal species occur naturally in the environment and can become endemic to a farm (Yanong \& Francis-Floyd 2006), suggests that their detection and elimination may prove problematic.

In Bioassay 3 a total of 10 shrimp were experimentally infected by injection with the Streptococcus sp. isolate and died within $3 \mathrm{~d}$ PI as in Bioassay 1. Multiple freezing and thawing trials of 5 shrimp held at $-20^{\circ} \mathrm{C}$ and 5 held at $-80^{\circ} \mathrm{C}$ were then conducted. After a total of 5 freeze-thaw cycles over a 2 mo period, the Streptococcus sp. organism was successfully cultured from the ventral sinus of all 10 shrimp on each occasion. These results demonstrate that the isolate used in this series of studies is highly resistant to long-term freezing and multiple freeze/thaw cycles and differences in freezing temperatures had no apparent effect on the organism's viability.

The collective findings of this study establish the existence of a new streptococcal disease of penaeid shrimp that can potentially spread to other countries through either live or frozen infected shrimp. Research emphasis needs to focus on developing PCR primers for the detection of this Streptococcus sp., identifying the source(s) of the bacteria and developing a management plan for the prevention, containment and treatment of future outbreaks.

Acknowledgements. Our appreciation and thanks to Dr. P. Frelier for his editorial comments concerning this manuscript. The authors also express their gratitude to Shrimp Improvement Systems and Dr. G. Jaramillo for supplying the SPF test shrimp used in this study, to Ziegler Bros. and Ms. C. Shew for supplying the feed used in this study and to Dr. T. Samocha for his continued support and contributions to our bioassay system.

\section{LITERATURE CITED}

Almeida RA, Oliver SP (1995) Invasion of bovine mammary epithelial cells by Streptococcus dysgalactiae. J Dairy Sci 78:1310-1317

Baeck GW, Kim JH, Gomez DK, Park SC (2006) Isolation and characterization of Streptococcus sp. from diseased flounder (Paralichthys olivaceus) in Jeju island. J Vet Sci 7:53-58

Bell T, Lightner DV (1988) A handbook of normal penaeid shrimp histology. World Aquaculture Society, Baton Rouge, LA

Berridge BR, Fuller JD, Azavedo J, Low DE, Bercovier H, Frelier PR (1998) Development of specific nested oligonucleotide PCR primers for the Streptococcus iniae 16S-23S ribosomal DNA intergenic spacer. J Clin Microbiol 36: 2778-2781

Brock JA, Main KL (1994) A guide to the common problems and diseases of cultured Penaeus vannamei. World Aquaculture Society, Baton Rouge, LA

> Camus AC, Shewmaker PL, Mauel MJ, Wise DJ (2008) Streptococcus ictaluri arthritis, osteolysis, myositis, and spinal meningitis in channel catfish broodstock. J Aquat Anim Health 20:54-62
Carson FL (1997) Histotechnology - a self instructional text, 2nd edn. American Society of Clinical Pathologists, Chicago, IL

Cheng W, Chen JC (1998) Isolation and characterization of an Enterococcus-like bacterium causing muscle necrosis and mortality in Macrobrachium rosenbergii in Taiwan. Dis Aquat Org 34:93-101

Currás M, Magariños B, Toranzo AE, Romalde JL (2002) Dormancy as a survival strategy of the fish pathogen Streptococcus parauberis in the marine environment. Dis Aquat Org 52:129-136

Dawson CR, Mallette MF (1945) The copper proteins. In: Anson ML, Edsall JT (eds) Advances in protein chemistry. Elsevier, Amsterdam, p 179-248

Eldar A, Bejerano Y, Livoff A, Hurvitz A, Bercovier H (1995) Experimental streptococcal meningo-encephalitis in cultured fish. Vet Microbiol 43:33-40

Eldar A, Perl S, Frelier PF, Bercovier H (1999) Red drum Sciaenops ocellatus mortalities associated with Streptococcus iniae infection. Dis Aquat Org 36:121-127

Evans JJ, Shoemaker CA, Klesius PJ (2000) Experimental Streptococcus iniae infection of hybrid striped bass (Morone chrysops $\times$ Morone saxatilis) and tilapia (Oreochromis niloticus) by nares inoculation. Aquaculture 189:197-210

Frelier PF, Sis RF, Bell TA, Lewis DH (1992) Microscopic and ultrastructural studies of necrotizing hepatopancreatitis in Pacific white shrimp (Penaeus vannamei) cultured in Texas. Vet Pathol 29:269-277

> Hasson KW, Lightner DV, Poulos BT, Redman RM, White BL, Brock JA, Bonami JR (1995) Taura syndrome in Penaeus vannamei: demonstration of a viral etiology. Dis Aquat Org 23:115-126

> Hasson KW, Lightner DV, Mohney LL, Redman RM, White BM (1999) Role of lymphoid organ spheroids in chronic Taura syndrome virus (TSV) infections in Penaeus vannamei. Dis Aquat Org 38:93-105

Hoshina T, Sano T, Morimoto Y (1958) A streptococcus pathogenic to fish (1933). J Tokyo Univ Fish 44:57-68

Jayarao BM, Dore JJE, Baumbach GA, Matthews KR, Oliver SP (1991) Differentiation of Streptococcus uberis from Streptococcus parauberis by polymerase chain reaction and restriction fragment length polymorphism analysis of 16s ribosomal DNA. J Clin Microbiol 29:2774-2778

Koch R (1884) Die Aetiologie der Tuberkulose. Mitt Kaiserl Gesundheitsamte 2:1-88

Kusuda R, Kawai K, Salati F, Banner CR, Freyer JL (1991) Enterococcus seriolicida sp. nov., a fish pathogen. Int $\mathrm{J}$ Syst Bacteriol 41:406-409

Lancefield RC (1933) A serological differentiation of human and other groups of hemolytic streptococci. J Exp Med 57:571-595

Lightner DV (1996) A handbook of shrimp pathology and diagnostic procedures for diseases of cultured penaeid shrimp. World Aquaculture Society, Baton Rouge, LA

Meiri-Bendek I, Lipkin E, Friedmann A, Leitner G, Saran A, Friedman S, Kashi Y (2002) A PCR-based method for the detection of Streptococcus agalactiae in milk. J Dairy Sci 85:1717-1723

Ringo E, Gatesoupe FJ (1998) Lactic acid bacteria: a review. Aquaculture 160:177-203

> Romalde JL, Ravelo C, Valdés I, Magariños B and others (2008) Streptococcus phocae, an emerging pathogen for salmonid culture. Vet Microbiol 130:198-207

Rubens CE, Smith S, Hulse M, Chi EY, van Belle G (1992) Respiratory epithelial cell invasion by Group B streptococci. Infect Immun 60:5157-5163 
Saulnier D, Haffner P, Goarant C, Levy P, Ansquer D (2000) Experimental infection models for shrimp vibriosis studies: a review. Aquaculture 191:133-144

Shewmaker PL, Camus AC, Bailiff T, Steigerwalt AG, Morey RE, Carvalho MS (2007) Streptococcus ictaluri sp. nov., isolated from channel catfish Ictalurus punctatus broodstock. Int J System Evol Microbiol 57:1603-1606

Sindermann CJ, Lightner DV (1988) Disease diagnosis and control in North American marine aquaculture. Elsevier Science Publishing, New York

Toranzo AE, Devesa S, Heinen P, Riaza A, Nunez S, Barja JL (1994) Streptococcosis in cultured turbot caused by an Enterococcus-like bacterium. Bull Eur Assoc Fish Pathol $14: 19-23$

Editorial responsibility: Grant Stentiford, Weymouth, UK
Vendrell D, Balcazar JL, Ruiz-Zarzuela I, de Blas I, Girones O, Muzquiz JL (2006) Lactococcus garvieae in fish: a review. Comp Immunol Microbiol Infect Dis 29:177-198

Wang PC, Lin YD, Liaw LL, Chern RS, Chen SC (2008) Lactococcus lactis subspecies lactis also causes white muscle disease in farmed giant freshwater prawns Marcrobrachium rosenbergii. Dis Aquat Org 79:9-17

Yanong R, Francis-Floyd R (2006) Streptococcal infections of fish. Circular FA057. Institute of Food and Agricultural Sciences, University of Florida, Miami, FL, p 1-6

Zlotkin A, Chilmonczyk S, Eyngor M, Hurvitz A, Ghittino C, Eldar A (2003) Trojan horse effect: phagocyte-mediated Streptococcus iniae infection of fish. Infect Immun 71:2318-2325

Submitted: March 19, 2009; Accepted: August 20, 2009 Proofs received from author(s): September 14, 2009 